\title{
BIRD POPULATIONS IN A BLACK COTTONWOOD \\ COMMUNITY, GRAND TETON NATIONAL PARK
}

\author{
Kenneth L. Diem \\ Department of Zoology and Physiology \\ University of Wyoming \\ Laramie
}

\begin{abstract}
Baseline information on the avifauna of the riparian communities in Grand Teton National Park is sparse. Consequently, the objective of this project is to collect information on the composition, density, distribution and habitat of the bird species inhabiting a portion of the black cottonwood, Populus trichocarpa, community in Grand Teton National Park. The study was initiated in June 1980 on a portion of the western lloodplain of Pilgrim Creek. The southeast corner of this $300 \mathrm{~m} \times 400 \mathrm{~m}$ (12ha) plot is identified by a metal post. This post can be located on a bearing line of $4^{\circ} \mathrm{E}$ of $\mathrm{N} .77 \mathrm{~mm}$ from the fiducial center of the infrared aerial photo N 31 (JJ.S. Bur. of Reclamation Series B/RI7, 7-16-79).
\end{abstract}

This floodplain cornmunity is predominantly black cottonwood with scattered trees of quaking aspen, Populus tremuloides, engelman spruce, Picea engelmannii and lodgepole pine, Pinus contorta. In restricted moister areas several small patches of alder, Alnus incana occur under the larger trees and a few patches of willow, (Salix, sp.) are located in moist openings of the woodland.

\section{Methods}

The mapping census plot was subdivided into 12 square 1 ha plots, with a 30 in. metal post at each hectare corner. Painted wooden stakes were used to mark the $50 \mathrm{~m}$ intervals between each corner stake.

All censuses were begun at 7:30 am and ended between 9:30 and 10 am following procedures set forth by the International Bird Census Committee (Svensson, 1970). Each bird observation on the plot was recorded as to species, number, sex and age and activity of the individuals and location. Movements of the census taker through each plot were such that at no time was the width of the area being censused greater than $33 \mathrm{~m}$. This was accomplished by the census taker using a census pattern which moved through nine square subunits approximately $33 \mathrm{~m}$ on a side.

\section{Results}

Study plot censuses were taken on June 10-15 and on July 7-10. A summary of the numbers of birds in the 24 species observed is presented in Table 1. Numbers of two species declined sharply, the American Robin $(-56 \%)$ and the Western Wood Pewee $(-87 \%)$ when compared to the $\bar{X}$ of the $1980-81$ seasons. It may be, that late spring and early summer being very wet was a factor in these 


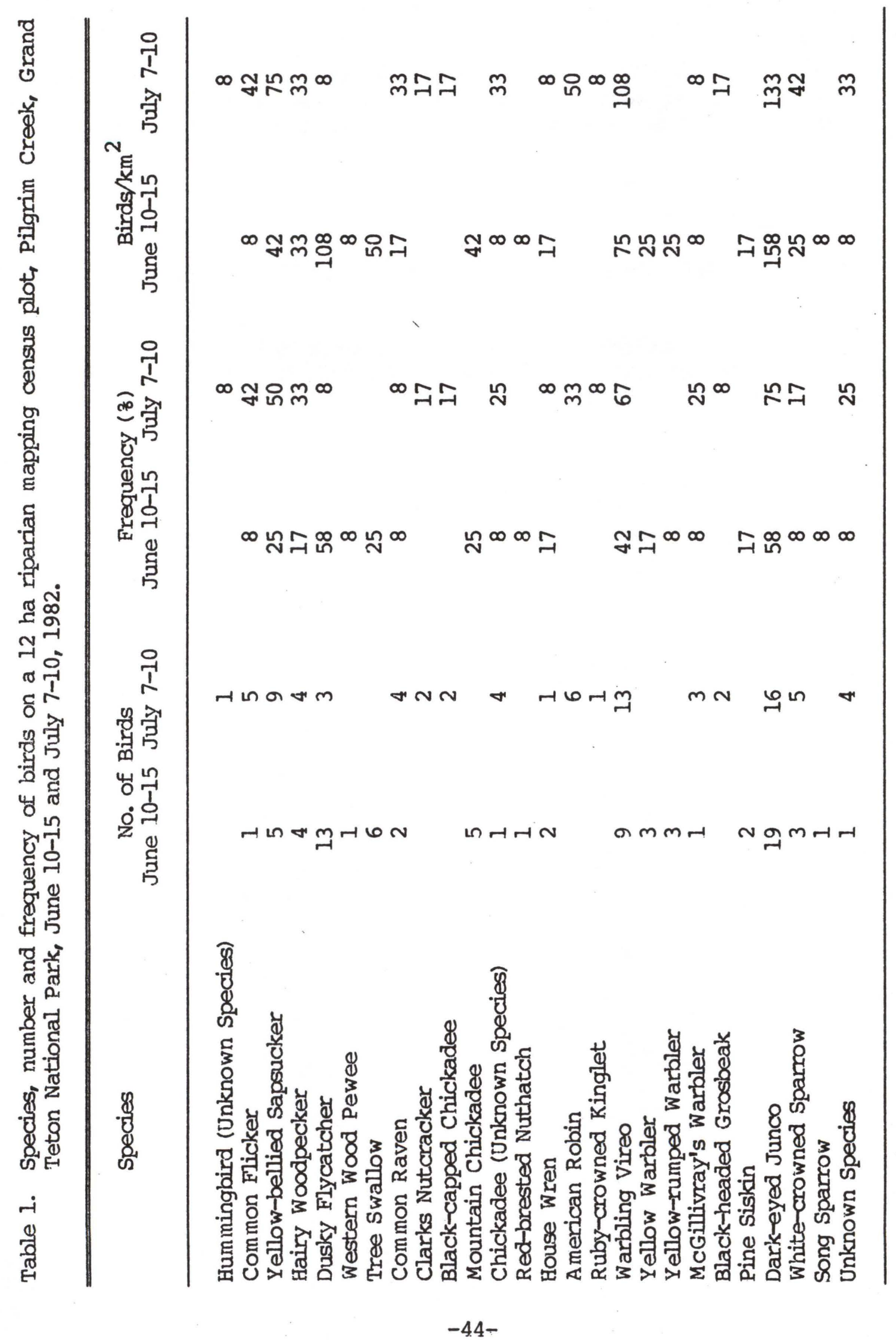


declines. Of the 24 species on the study area, the Dark-eyed Juncos and the Warbling Vireos were the most abundant. Also, these two species and the Yellow-bellied Sapsucker were likely to be encountered anywhere on the study area.

\section{Iiterature Cited}

Skaar, P. 1969. Birds of the Bozeman latilong. 501 S. Third, Bozeman, Montana. 131 p.

Svensson, S. (Editor). 1970. Bird census work and environmental monitoring. Swedish Natural Science Research Council, Redaktionstjansten, Stockholm. $52 \mathrm{p}$. 